\title{
Development of hard intermetallic coatings on austenitic stainless steel by hot dipping in an Al-Si alloy
}

\author{
E. Frutos, ${ }^{\text {b,a }}$ J.L. González-Carrasco, ${ }^{\text {a,b }}$ C. Capdevila, ${ }^{\text {a }}$ J.A. Jiménez, ${ }^{\text {a }}$ Y. Houbaert ${ }^{\mathrm{c}}$ \\ ${ }^{a}$ Centro Nacional de Investigaciones Metalúrgicas, CENIM-CSIC, 28040 Madrid \\ ${ }^{b}$ Centro de Bioingeniería, Biomateriales y Nanomedicina, CIBER-BBN, Instituto de Salud \\ Carlos III, España \\ ${ }^{c}$ Department of Metallurgy and Materials Science, Ghent University, Belgium
}

\begin{abstract}
The austenitic stainless steel was coated by dipping into a molten Al-12.4\%Si alloy at $765^{\circ} \mathrm{C}$. The effect of immersion times in the range of 60 to $900 \mathrm{~s}$ was investigated with respect to the phase nature, thickness, and microhardness. An uniform layer $(\sim 12 \mu \mathrm{m})$ of $\mathrm{Al}_{12}(\mathrm{Fe}, \mathrm{Cr})_{3} \mathrm{Si}_{2}$ intermetallic with hexagonal crystalline structure is formed, irrespectively the immersion time. Microhardness of the coating decreases with increasing dipping time, ranging between 850 and $600 \mathrm{HV}$ for the shortest and longest immersion time, respectively. These hardness values are higher than that of about 200 HV for the substrate, which was not affected for the investigated periods of immersion.
\end{abstract}

\section{Keywords}

Austenitic stainless steel; Coating; Intermetallic compounds; Microhardness; Siliconization 


\section{Introduction}

Surface siliconization by immersion in a liquid Al-Si alloy is a low cost technique that has been successfully used to develop stable Si-rich coatings, enhancing magnetic properties of ferritic steels [1,2] or oxidation resistance of Ti-aluminides [3]. This investigation was aimed to explore the potential of siliconization in improving the biofunctionality of the 316 LVM austenitic stainless steel. Rationale for this proposal is that the resulting coating will have a passive film enriched in $\mathrm{Si}$, which could enhance the biological and corrosion in vitro response as occurs with the sol-gel coatings [4].

Through the analysis of previous works on siliconization of ferritic alloys it follows that morphology, nature, and thickness of the coating strongly depends on the processing conditions $[1,2]$. Moreover, the nature of the steel investigated in this work, with a fcc structure and with a high $\mathrm{Ni}$ and $\mathrm{Cr}$ content among others, may affect the stability of the phases formed in the coating. For example, the presence of $\mathrm{Sr}$ and other elements such as $\mathrm{Mn}$ and $\mathrm{Cr}$ can encourage the development of the $\alpha$ phase, with a dendritic morphology, at the expense of $\beta-\mathrm{Al}_{5} \mathrm{FeSi}$ [5], which is characterized as brittle. Moreover, the $\alpha$ phase presents many different compositions $[6,7,8,9,10]$, although the most stable is the $\mathrm{Al}_{8} \mathrm{Fe}_{2} \mathrm{Si}$ [11]. All these considerations confirm the necessity of individual optimization of the processing parameters. The purpose of this work is therefore to investigate the microstructural evolution of the 316LVM stainless steel during hot dipping in a molten Al-12.4\% Si eutectic alloy. The effect of the immersion times will be investigated with respect to the phase nature, thickness, and microhardness of the coating.

\section{Materials and methods}


The investigated material was the austenitic stainless steel 316 LVM used for medical applications. Its chemical composition is summarised in Table 1. Hot dipping was conducted in a vertical furnace, which housed a crucible of mullite with a capacity of approximately $410 \mathrm{~cm}^{3}$. Before dipping, the samples were cleaned in a dissolution of $40 \%$ of nitric acid, washed in running water and sonicated with ethanol. Then, they were introduced in the bath of $\mathrm{Al}-12.4 \% \mathrm{Si}$ at a temperature of $765^{\circ} \mathrm{C}$ without any preheating. The immersion times ranged between $60 \mathrm{~s}$ and $900 \mathrm{~s}$. Once extracted from the bath, the samples were cooled out of the crucible to ambient temperature.

Microstructural characterization of the coating was conducted using both, scanning electron microscopy (SEM) and X-ray diffraction (XRD). Microstructure was studied by using a field emission gun scanning electron microscope, (FEG-SEM) Jeol JSM6500F coupled with an energy dispersive X-ray (EDX) system for chemical microanalysis. XRD measurements were carried out with a Bruker AXS D8 diffractometer. The studies were conducted in coated samples, once removed the remnant outer layer of Al-Si alloy using chemical and mechanical polishing. The Pawley and LeBail methods were used for the full profile refinement and determination of lattice parameters. A version 4.0 of the analysis program TOPAS (Bruker AXS) was used. Isothermal sections of the Al-Fe-Si ternary diagram were determined by using the MTDATA software. Mechanical properties were determined by Vickers microhardness measurements performed on polished cross sections along lines perpendicular to the coated surface. These tests were carried out in a Wilson equipment by using a load of 10 $\mathrm{g}$ and $15 \mathrm{~s}$ of dwell time

\section{Results and discussion}


Siliconization of the austenitic stainless steel developed a homogeneous and continuous layer, about $12 \mu \mathrm{m}$ thick, which morphology and thickness does not significantly change with increasing immersion time. As an example, Figure 1 show a cross sectional view revealing the coating developed after $300 \mathrm{~s}$ of immersion. Three zones can be distinguished in the image; the steel substrate, the coating, and the remnant of $\mathrm{Al}-\mathrm{Si}$ liquid alloy adhered to the coating after dipping. This outer layer has been obviously eliminated for some tests but in this case was left to preserve the integrity of the coating during preparation of the cross section. The coating exhibits a fine columnar microstructure that according to Munson is characteristic of the $\alpha$-phase [7].

It is worth to remark that the steel-coating interface is flat, without signs of spallation. This morphology contrast with the tongue-like coating/substrate interface described for hot dipping of steels in molten aluminium $\left[{ }^{12},{ }^{13}\right]$. Eggeler et al. [13] investigated the influence of $\mathrm{Si}$ and found that a $2 \mathrm{wt} \%$ addition acts on the solid state side reducing the growth rate of the coating. Although not indicated by the authors, a close examinations of their results reveals that $\mathrm{Si}$ also induce a change from inwards growth (pure $\mathrm{Al}$ ) to outwards growth (Al-Si alloy) of the coating. It is thought that both features, the reduction in the growth rate and the change in the mode of growth, favour the stability of the coating/substrate interface during growing of the coating.

The coating-Al alloy interface, however, is slightly rough that denotes that during processing the coating was growing predominantly outwards. The small dark zones observed at the outer half part of the coating correspond to Al-Si alloy trapped during thickening of the coating, likely during the cooling stage. Etching of the specimen clearly reveals the dendritic structure, which is more evident at the outer part of the 
coating (see inset of Fig.1). This growth is fostered both by the presence of $\mathrm{Cr}$ as well as by the high rate of cooling [14].

Microanalysis of the coating and adjacent areas revealed that content of major elements remains constant through the thickness for all studied immersion times. Fig. 2 shows the depth profiles of elements forming the coating for a sample immersed for $300 \mathrm{~s}$. As can be seen, the concentration (at \%) of $\mathrm{Al}$ was high, at around $70 \%$, with an $11 \%$ of Fe and $\mathrm{Si}$, and $5 \%$ for $\mathrm{Cr}$. Interesting to note the absence of compositional gradients beneath the substrate despite the ingress of $\mathrm{Fe}$ and $\mathrm{Cr}$ into the coating. This unexpected result could result from the low growth rate of the coating, associated to the presence of $\mathrm{Si},[13]$ which allows to reach an equilibrium close to the coating/steel interface.

Determination of the nature of the coating from the above analysis is not possible since a number of $\mathrm{Al}_{\mathrm{x}} \mathrm{Fe}_{\mathrm{y}} \mathrm{Si}_{\mathrm{z}}$ type intermetallic compounds, with small differences in concentration, may form [15]. Assuming that the equilibrium conditions are achieved at the steel/Al-Si alloy interface, the equilibrium ternary diagrams becomes an useful tool to determine the type of intermetallic formed at the coating. Taking into account that cooling of the coated specimen out of the furnace is relatively fast, phases predicted by the diagram corresponding to the melt temperature $\left(765^{\circ} \mathrm{C}\right)$ were taken as a guide. The ternary diagram calculated predicts the formation of the $\mathrm{Al}_{3} \mathrm{Fe}$ and $\gamma-\mathrm{Al}_{3} \mathrm{Fe}{ }_{3} \mathrm{Si}$ intermetallics. However, the lack of significant variations in the chemical composition through the coating, Fig.1, and the monotonic contrast of the backscattered electron images, Fig. 2a, suggests the formation of a single Al-Fe-Si intermetallic compound, whose content in Fe is lower than that corresponding to the $\gamma-\mathrm{Al}_{3} \mathrm{Fe}_{3} \mathrm{Si}$ intermetallic. This discrepancy can result from the fact that the metallic sample was introduced into 
the melted alloy from the ambient temperature (without preheating), producing a decrease in the temperature of the melted alloy at the steel/Al-Si alloy interface. Analysis of the isothermal sections at lower temperatures indicates the possibility to form intermetallics type $\alpha$ and $\beta$ having Fe and Si contents compatible with the EDX analysis. As an example, Figure $2 \mathrm{~b}$ shows the isothermal section at $600{ }^{\circ} \mathrm{C}$ for the Alrich corner of the Al-Fe-Si diagram. This section indicates the possible formation of primary crystals of $\mathrm{Al}$ and of the intermetallics $\tau_{4}$ ( $\gamma$-phase, with tetragonal structure), $\tau_{5}$ ( $\alpha$-phase, with hexagonal structure) and $\tau_{6}$ ( $\beta$-phase, with monoclinic structure), resulting from a peritectic reaction [16]. Chemical composition of the coating signalled by the intersections of the corresponding compositional lines in the ternary diagram indicates the formation of $\mathrm{Al}_{8} \mathrm{Fe}_{2} \mathrm{Si}\left(\alpha\right.$-phase) and $\mathrm{Al}_{5} \mathrm{FeSi}(\beta$-phase).

To confirm the nature of the coating and to investigate possible changes with increasing immersion time, XRD analysis was performed on samples immersed for 90, 120, 300 and $900 \mathrm{~s}$. The representative diffractograms are presented in Fig. 3. The lattice parameters were calculated by the LeBail method of profile matching. The data reported for the $\alpha-\mathrm{Al}_{8} \mathrm{Fe}_{2} \mathrm{Si}$ phase in the ICDD data base (PDF 41-0894) were used as starting values for the refinement. Table 2 shows both, the lattice parameters after refinement and the data of the $\alpha$-phase published in the Joint Committee for Powder Diffraction Standards (JCPS). From the analysis of these data it follows that the phase forming the coating is the intermetallic $\mathrm{Al}_{12}(\mathrm{Fe}, \mathrm{Cr})_{3} \mathrm{Si}_{2}$ with an hexagonal structure identical to that of the intermetallic $\alpha-\mathrm{Al}_{8} \mathrm{Fe}_{2} \mathrm{Si}$, irrespectively the immersion time. This result is in contradiction with the suggestion of Munson [7] that states a change in the crystalline structure of $\mathrm{Al}_{12}(\mathrm{Fe}, \mathrm{Cr})_{3} \mathrm{Si}_{2}$ from hexagonal to cubic for $\mathrm{Cr}$ contents higher than 0.03 
wt-\%. Stability of the coating with increasing immersion time would confirm the stabilizing role of $\mathrm{Cr}$.

Hardness measurements were performed at the inner part of the coating thickness, at places where Al-rich zones were not observed. Fig. 4 shows the evolution of hardness of the coating with increasing immersion time. As can be seen, hardness decreases from $850 \mathrm{HV}$, for the shortest immersion time, up to about $600 \mathrm{HV}$ for the longest immersion time. Such values are higher than that of about $200 \mathrm{HV}$ for the substrate, which was not affected for the investigated periods of immersion. Given the absence of changes in the chemical composition and crystallographic structure of the coating, the decrease in its hardness with increasing immersion time could be related with an increase in the grain size and/or changes in the residual stress state that are being investigated. It is worth to notice that indentation did not cause delamination at the coating/steel interface, denoting that the coating is tightly adhered to the substrate (see inset of Fig.4). The absence of cracks around the footprints highlights the good ductility of the coating that contrasts with the inherent brittle behaviour that characterizes the intermetallic compounds. This apparent good ductility is likely associated to the existence of a very fine grain size structure, which has been proved to be a prerequisite to get some ductility $\left[{ }^{17}\right]$.

Regarding the potential of the coated steel for medical applications in vitro experiments, including corrosion and cytobiocompatibility tests, are in progress. Preliminary results indicate that coating of the alloy does not compromise the good corrosion behaviour and cytobiocompatibility of the austenitic stainless steel $\left[{ }^{18}\right]$. Additional advantages related to the absence of $\mathrm{Ni}$ in the coating are expected. 


\section{Conclusions}

- Hot dipping of $316 \mathrm{LVM}$ steel in a molten $\mathrm{Al}-12 \% \mathrm{Si}$ alloy at $765^{\circ} \mathrm{C}$, for immersion times in the range of 60 to $900 \mathrm{~s}$, develops on the surface a relatively thick coating $(\sim 12 \mu \mathrm{m})$ consisting of an intermetallic type $\mathrm{Al}_{12}(\mathrm{Fe}, \mathrm{Cr})_{3} \mathrm{Si}_{2}$, with a crystallographic structure identical to that of the $\alpha-\mathrm{Al}_{8} \mathrm{Fe}_{2} \mathrm{Si}$ intermetallic, irrespectively the immersion time.

- The developed coating is tightly adhered to the substrate, exhibiting a high hardness and a good ductility. Microhardness of the coating decreases with increasing dipping time, ranging between 850 and $600 \mathrm{HV}$ for the shortest and longest immersion time, respectively. These hardness values are higher than that of about $200 \mathrm{HV}$ for the substrate, which was not affected for the investigated periods of immersion.

\section{Ackowledgements}

The authors thank financial support to Spanish Project MAT2006-12948-C04-01 and the CIBER of Bioingeniería, Biomateriales y Nanomedicina, which is supported by the ISCIII.

\section{References}

1 T. Ros-yañez, Y. Houbaert, J. Appl. Phys. 91 (2002) 7857.

2 T. Ros-Yañez, Y. Houbaert, O. Schneeweiss, J. Asensio, M. Prado, Rev. Metal. Madrid 36 (2000) 339.

${ }^{3}$ H.P. Xiong, W. Mao, W.L. Ma, Y.H. Xie, Y. Feng, H. Yuan, X.H. Li, Mater. Sci. Eng. A, 433 (2006) 108.

${ }^{4}$ J. Gallardo, P. Galliano, A. Duran, J Sol-Gel Sci. Technol., 21 (2001) 65. 
5 A. Couture, AFS Int. Cast. Met. J. 6 (1981) 9.

${ }^{6}$ G.J. Pharagmen, Inst. Met. 77 (1950) 489.

${ }^{7}$ D.J. Munson, Inst. Met. 95 (1967) 217.

8 J.E. Tibballs, Key. Eng. Mater. 44 (1990) 233.

9 J.G. Zheng, R.Vincent, J.W. Steeds, Philos. Mag. 80 (2000) 493.

${ }^{10}$ J.G. Zheng, R.Vincent, J.W. Steeds, Philos. Mag. 79 (1999) 2725.

${ }^{11}$ L.F. Mondolfo, Aluminium Alloys: Structure and Properties. London: Butterworths and Co., Ltd.; 1976.

${ }^{12}$ F. Barbier, D. Manuelli, K. Bouché, Scr. Mater. 36 (1997) 425.

${ }^{13}$ G. Eggeler, W. Auer, H. Kaesche, J. Mater. Sci. 21 (1986) 3348-3350.

${ }^{14}$ L.A. Narayanan, F.H. Samuel, J.E. Gruzleski, Metal Mater. Trans. A 26 (1995) 2161.

${ }^{15}$ V.G. Rivlin, G.V. Raynor, Int. Met. Rev. 3 (1981)133.

${ }^{16}$ S.P. Gupta, Mater. Charact. 49 (2003) 269.

${ }^{17}$ J. Chao, D.G. Morris, M.A. Muñoz-Morris, J.L. González-Carrasco, Intermetallics 9 (2001) 299.

${ }^{18}$ E. Frutos, J.L. González-Carrasco, L. Saldaña, M. Multigner, and N. Vilaboa. In Proceedings of $\mathrm{X}$ Congreso Nacional de Materiales, Mondragón Unibersitateko Zerbitzu Editoriala, Arrasate-Mondragon, 2008, pp 615-618. 


\section{Figure captions}

Figure 1. Backscattered Electron Image obtained on a cross section corresponding to a sample that was hot dipped for $300 \mathrm{~s}$. The inset shows an optical micrograph that reveals the dendritic structure of the coating (etched specimen).

Figure 2. (a) Profile analysis through the coating for a sample hot dipped during $300 \mathrm{~s}$. (b) Isothermal section at $600{ }^{\circ} \mathrm{C}$ of the Al-rich corner of the Al-Fe-Si diagram. Chemical composition of the coating, signalled by the intersections of the corresponding compositional lines in the ternary diagram, indicates the formation of $\mathrm{Al}_{8} \mathrm{Fe}_{2} \mathrm{Si}(\alpha-$ phase) and $\mathrm{Al}_{5} \mathrm{FeSi}(\beta$-phase).

Figure 3. Comparison of XRD spectra for the coatings developed with different immersion times and the $\alpha-\mathrm{Al}_{8} \mathrm{Fe}_{2} \mathrm{Si}$ standard.

Figure 4. Microhardness of the coating as a function of the immersion time. The inset shows an optical micrograph that reveals the microhardness footprints in a sample hot dipped for $300 \mathrm{~s}$. 
Tabla 1.

Tabla 1. Chemical composition (wt \%).of AISI 316 LVM steel.

\begin{tabular}{|c|c|c|c|c|c|c|c|}
\hline Element & $\mathrm{C}$ & $\mathrm{Si}$ & $\mathrm{Mn}$ & $\mathrm{Cr}$ & $\mathrm{Ni}$ & $\mathrm{Mo}$ & $\mathrm{Fe}$ \\
\hline$\%$ Weight & 0,03 & 1,00 & 2,00 & 17,00 & 12,00 & 2,50 & Balance \\
\hline
\end{tabular}


Table 2. Crystallographic data of the $\alpha$-phase according to the JCPS files and data obtained in the present work

\begin{tabular}{|c|c|c|c|c|c|}
\hline \multirow{2}{*}{ Compound } & \multirow{2}{*}{ Source } & \multicolumn{3}{|c|}{$\begin{array}{c}\text { Composition } \\
\text { (wt.\%) }\end{array}$} & \multirow{2}{*}{$\begin{array}{c}\text { Crystal Structure } \\
\text { Lattice Parameter }(\mathrm{nm})\end{array}$} \\
\cline { 3 - 5 } & & $\mathrm{Al}$ & $\mathrm{Fe}$ & $\mathrm{Si}$ & \\
$\alpha-\mathrm{Al}_{8} \mathrm{Fe}_{2} \mathrm{Si}$ & $\begin{array}{l}\text { JCPS } 41- \\
0894\end{array}$ & 60.6 & 31.6 & 7.8 & Hexagonal: $\mathrm{a}=1.24, \mathrm{c}=2.62$ \\
$\alpha^{\prime}-\mathrm{Al}_{12}(\mathrm{Fe}, \mathrm{Cr})_{3} \mathrm{Si}_{2}$ & \begin{tabular}{l} 
This study \\
\hline
\end{tabular} & 60.3 & 29.2 & 10.5 & Hexagonal: $\mathrm{a}=1.26, \mathrm{c}=2.60$ \\
\hline
\end{tabular}



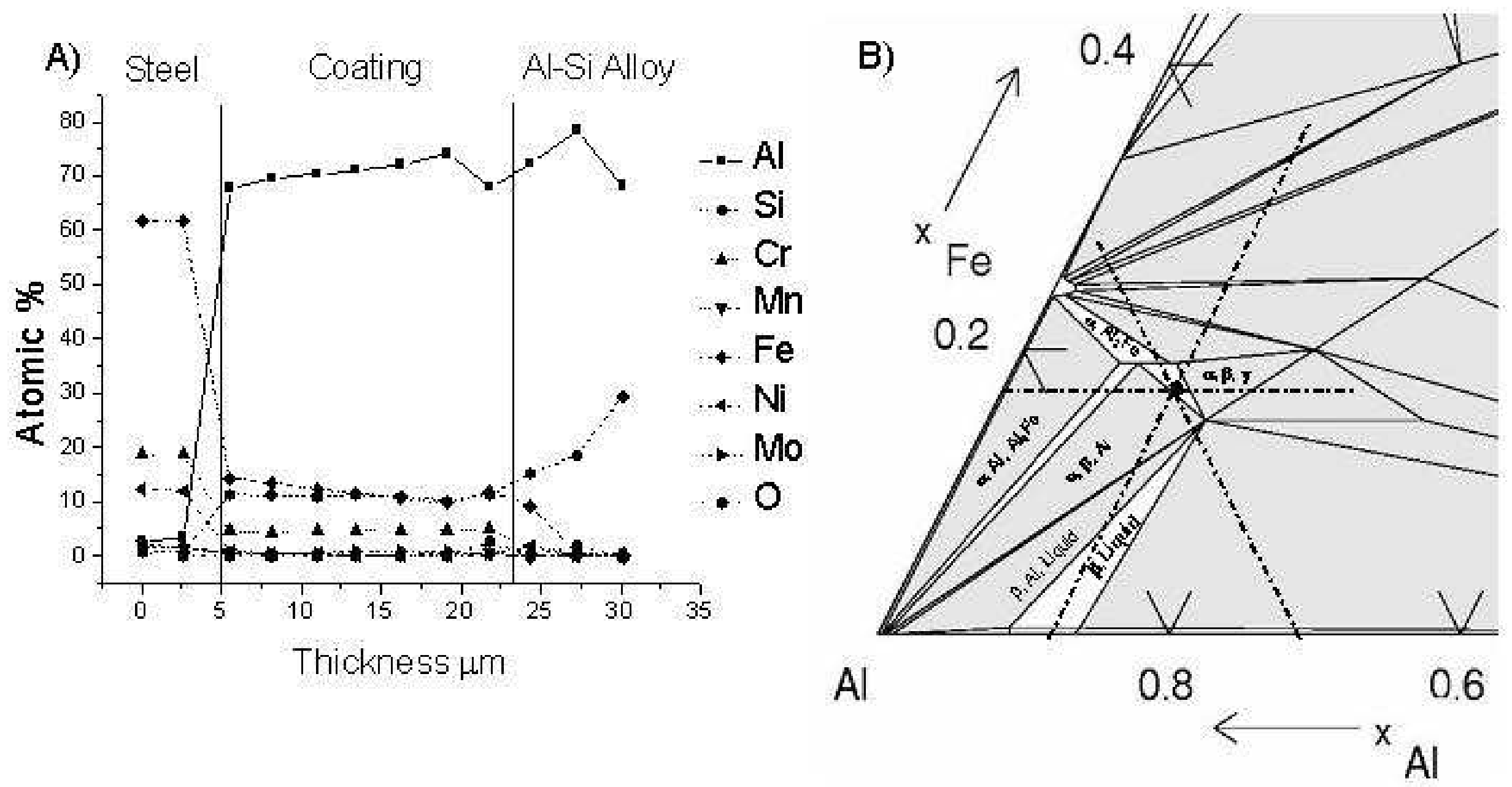


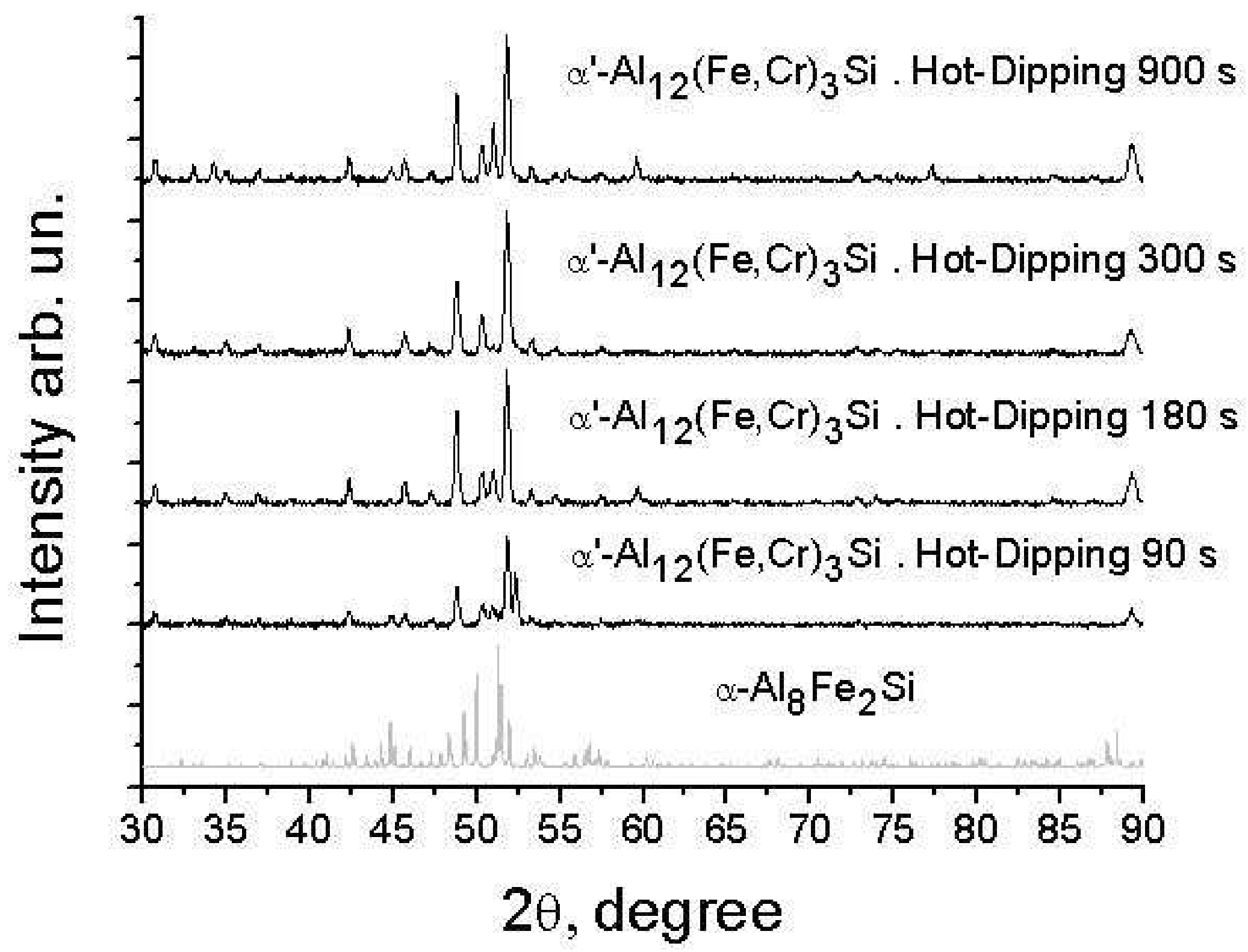




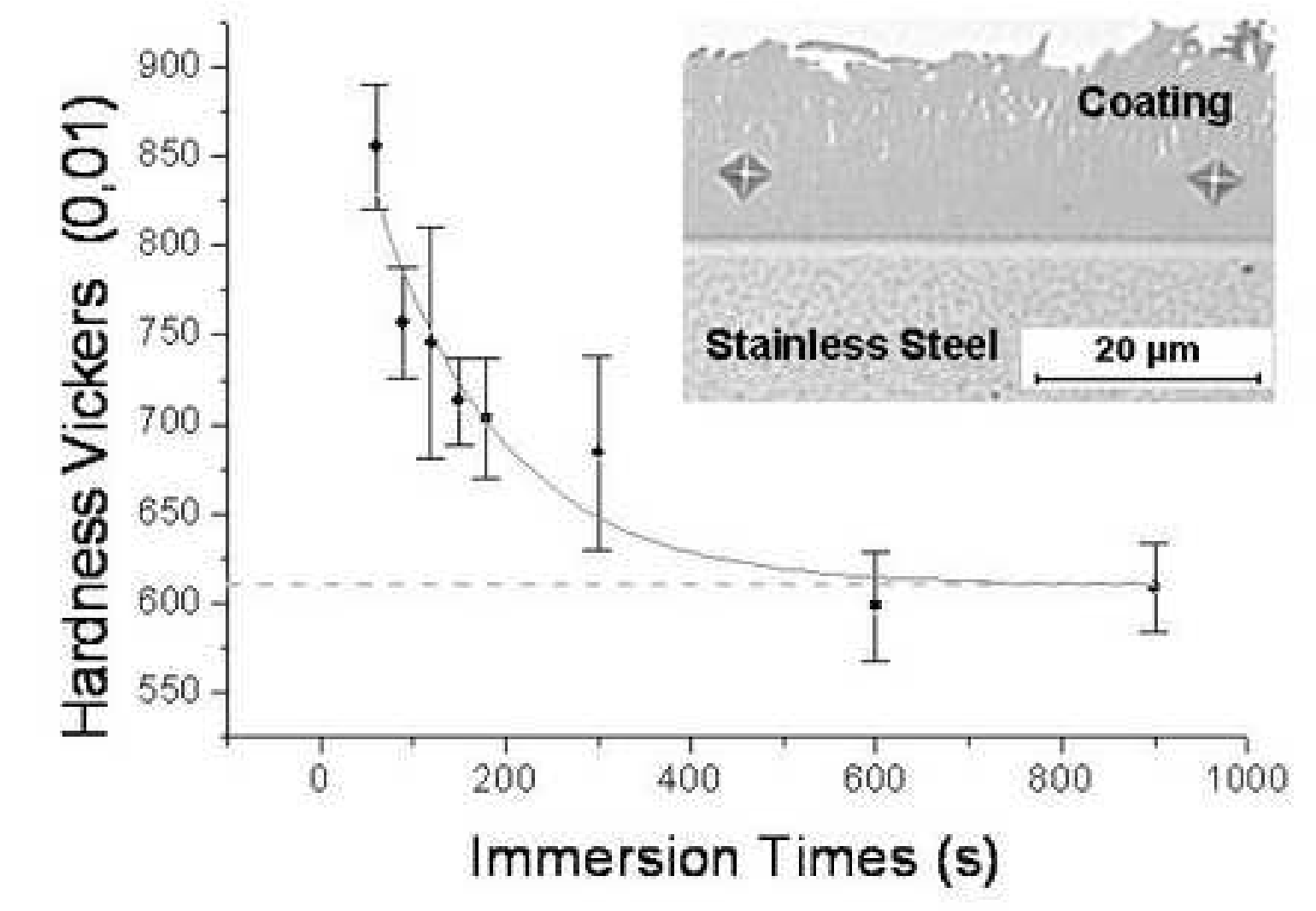

